\title{
Different Images of Knowledge and Perspectives of Pedagogy in Confucius and Socrates
}

\author{
ZHONG JIANWEI
}

Ningbo University (China)

\begin{abstract}
Confucius and Socrates, two cultural icons of the East and West, both declared they did "not know," which, however, held different concepts for them. First, I will critically examine their dialogue teaching practices to analyze the implications of "knowing" and "not knowing." Second, I will explore the different images of knowledge and visions of pedagogy each held.
\end{abstract}

Confucius and Socrates, two cultural icons of the East and West, both declared they did "not know." Confucius said, "Am I indeed possessed of knowledge? I do not know." Socrates said, "As for me, all I know is that I know nothing."

The two cultural icons established their unique images of knowledge: I do not know. There are, however, rich and different implications behind their similar declarations of "not knowing." Next, I will critically examine their dialogue teaching practices to analyze what they meant by "knowing" and "not knowing." In this sense, I will explore the different images of knowledge and visions of pedagogy in Confucius and Socrates.

\section{Declarations of "I do not know" by Confucius and Socrates}

Confucius and Socrates both declared "I do not know." But Confucius declared this with reference to a particular situation. In Part IX of The Analects of Confucius, Confucius says, "Am I indeed possessed of knowledge? I do not know. But if an ignorant person, who appears quite empty-like, asks anything of me, I set it forth from one end to the other, and exhaust it"(Fan Zhang, 1995, 76) ${ }^{1}$. There are controversies about the annotation of this paragraph which was originally written in ancient script. People usually suppose it was Confucius who was empty-like. This supposition was inferred logically from the first half of the paragraph, namely, "Am I indeed possessed of knowledge? I do not know," For example, Xionggen Zhao (1994), a famous professor of Soochow University, explains that "a mean person came to Confucius for advice. Unfortunately Confucius had no relevant knowledge" (p. 165). But Mu Qian, a

${ }^{1}$ In this statement of an ignorant person, often translated as a "mean" person, the implication is that the person is not only ignorant but also rude. 
renowned representative of the modern new Confucianism who has died, paid more attention to the logic of the rear half of the paragraph and inferred that it was the mean person who was "empty-like" (Qian, 2002, p. 227). The above Chinese-English translation of this paragraph is in accordance with Mu Qian's interpretation.

Is it Confucius or the mean person who was "empty-like"? This is not an inconsequential matter for understanding about the pedagogical implication of Confucius's declaration "I do not know." Confucius was heartfelt to declare himself "not knowing," if it was he who was "empty-like." Confucius had no ready-made answer to the ignorant person's inquiry. So he was forced to adopt a kind of dialogic method, namely, setting it forth from one end to the other and exhausting it, to solve the ignorant person's doubt. If it was the ignorant (and rude) person who was empty-like, Confucius's declaration had a direct, active pedagogical implication. Therefore, in fact, Confucius did not really "not know." He concealed his answer intentionally and adopted actively the kind of pedagogic art characteristic of dialectics. In this sense, this pedagogic method comes closer to Socrates's "Midwife's Art."

A series of events stimulated Socrates to declare himself "knowing nothing." When he was 27, the most authoritative Delphic Oracle pronounced that "nobody is cleverer than Socrates." But Socrates refused to jump at the pronouncement immediately just for the fact it was pronounced by the Delphic Oracle. Instead, he scoured the whole city to talk to the men who were reported to be cleverest. Finally Socrates found that these people weren't really clever. Finally he found that "he was clever because he knew he knew nothing" (Ronald Gross, 2005, p. 12). However, these "cleverest" men were in the plight of knowing nothing about their knowing nothing.

\section{Different meanings of "knowing" in Confucius and Socrates}

In fact, there were fundamental differences between the declarations "not knowing" of Confucius and of Socrates. The main point is the different implications of the word "know" underlying this statement.

Confucius thought about knowledge in the daily situation of life; this is to say, "in the place of daily life-use and behavior" (Liang, 2006, p. 2) which was said by Qichao Liang, a well-famed Enlightenment thinker, educationalist and historian in the modern time of Chinese history. He disliked metaphysical thinking and talking. His "not knowing" was concerned with the concrete problematical context of questions. If we think it was Confucius who was empty-like, then it means that Confucius recognized his knowledge structure to be defective and thus could not give a ready-made answer to the ignorant (rude or "mean") person.

Furthermore, Confucius closely connected "knowing" with "learning." The growth of knowledge is an endless process of increasing and accumulating. For Confucius, the reason for his failure to give a ready-made answer to the person was that his learning or knowledge accumulation was not enough. To grasp all knowledge and solve all difficulties is an unattainable goal in our whole life because the infinite universe is very complex and uncertain. This is just as Chuang-Tzu said, "life is limited, while knowledge is infinite" ${ }^{2}$ (Kanglei Zhong, 1996, p. 33).

All in all, Confucius saw learning as a link between "knowing" and "not knowing." This means that the declaration "I do not know" should be interpreted from a perspective of learning. Being not knowing is just a normal phenomenon, step or stage in the process of knowledge learning and accumulation. The state of being not knowing

\footnotetext{
${ }^{2}$ Chuang-Tzu was one of the main founders of Taoism who lived from about 369 BCE until about 286 BCE. This famous sentence of Chuang-Tzu is broadly hung on the walls of Chinese classrooms to encourage the students to cherish the time and study hard. But the original meaning in Chuang-Tzu was largely to deny the significance of learning knowledge.
} 
has both an eternal and temporary nature. It is eternal because the process of learning is everlasting. It is temporary because it is only an interim state and can be made up by leaning. Also, knowledge is situational, which fact is embodied in Confucius's answers varying with different individuals and matters.

"Knowing," however, has fundamentally different signification in Socrates's Dialogues. Socrates was extremely broad in learning, which could be reflected in the rich examples in his dialogues. He was fond of reading and traveling. Especially, he was good at learning from others. Therefore, Socrates didn't actually know nothing on the side of experiential knowing. The truth was the exact opposite.

So if we want to understand the significations of "knowing" and "not knowing" which Socrates referred to, we must pay attention to the western tradition of epistemology rather than the experiential knowledge or the place of daily life-use and behavior.

For Socrates, the knowledge stemming from daily situations of experiences were not well-rounded because "experiential conclusion is particular rather than general" (Dewey, 2005, p. 18). Though Socrates often used experiential situations in his dialogues, his intention was basically to ask for aid from them to pose questions or to raise doubts about the definitions or conclusions of the other dialogists which were rooted in some other experiential situations. That is to say, Socrates constantly challenged the knowledge judgments of the other dialogists who relied on ex parte experiences and then sought for the general and certain truth which appeared actually to be inaccessible.

In short, Confucius put knowledge into experiential situations and daily life. His "not knowing" meant that he knew some things but couldn't know all things. On the contrary, Socrates seemed to go beyond experiential situations and daily life to search for the universal truth of knowledge. It seems that he meant that he knew nothing about anything. Thus, as far as his teaching was concerned, Confucius often helped the students to reach the state of "knowing" from "not knowing" by providing the exact answers with which the students enjoyed the feelings of both satisfaction and certainty. But Socrates, on the contrary, often pushed the process of the dialogues by shaking continuously the other persons' feelings of knowledge certainty. To be more exact, Socrates pushed the other dialogists into the uncertain state of "not knowing" from the certain feeling of "knowing." Since they had different understandings and implications of "knowing," if Confucius and Socrates had met and entered into a dialogue, Socrates would have questioned further the propositions and judgments of Confucius and criticized the way that Confucius set knowledge in the experiential situation and daily life-use and behavior.

The different cultural missions of Confucius and Socrates determined their own understanding of "knowing." In brief, Confucius was a moral philosopher of a social orientation. His educational thinking was formed by this social standard. His intention was to resume the civilizing social order, including its rituals and music, which had fallen into disfavor at that time. However, the orientation of Socrates was a personal standard. Unlike the civilizing mission of Confucius, Socrates undertook the mission of enlightening and awakening. He wanted to awaken the other dialogists to reflect on themselves and their subjectivities. This meant that what Socrates wanted was to help one person to liberate himself from his unjustifiable relation with the city-state or the gods and to discern himself ${ }^{3}$ from the others. In this way, a person could reflect and realize himself and then each could obtain individual liberation and find out her or his own subjectivities (Foucault, 2005).

\footnotetext{
${ }^{3}$ The use of the masculine noun here is representative of most, but certainly not all, Greek citystates.
} 


\section{Comparative study of the structure and feature of the dialogic teaching in Confucius and Socrates}

Next I will make further research into the dialogic teaching practices of the two icons and examine the tension between "not knowing" and "knowing."

Both Confucius and Socrates disliked writing books to expound their thoughts based on different reasons. Confucius didn't write books only because he "passed on the ancient culture without adding anything new to it and believed in and admired the ancients." Socrates didn't write books because he made a hierarchical difference between written language and speech. For him a written text would cause his thoughts to become outmoded, inflexible or dead. He said, "the reason I don't like writing books is that they can only repeat the same answer when you question them" (Gross, 2005, p. 10). So Socrates liked dialogic speaking rather than writing books. The most authentic thing was thoughts coming from the bottom of one's heart which could only directly be expressed by means of speech. Speech could keep thought alive and dynastic. Because they both didn't write books, I wonder whether their dialogic teaching practices were those in The Analects and the Dialogues. ${ }^{4}$ Especially, I wonder if The Analects oversimplifies Confucius's actual process of dialogic teaching. We can only assume that the two books really reflect the dialogic teaching process of the two thinkers.

Next I focus on the structures and features of the dialogic teachings of Confucius and Socrates to examine how they pushed their own dialogic teaching process along with the tension between "not knowing" and "knowing."

There were several dialogic forms in the School of Confucius, among which the form of question (by student) -and-answer (by Confucius) was the most prevalent one. For example, $\mathrm{Zi}$ Gong asked Confucius, "To be poor and yet not to be servile; to be rich and yet not to be proud, what do you say to that?" "It is good," replied Confucius, "but better still it is to be poor and yet contented; to be rich and yet know how to be courteous." The next form of dialogue was that Confucius questioned the students followed by the answers of the students. Then Confucius further evaluated or revised these answers. Additionally there were other forms of dialogue.

Whatever dialogic form was adopted, there are several obvious features in the dialogues of the School of Confucius. First, the process of these dialogues is very short. Second, accordingly, the dialogues lack the middle link of argument. That is to say, they lack the disputes, the oppositions, the challenges and so on. Thus they dramatically reduce and avoid dialogic complexity. Third, the dialogues appear as closed structures. The immediateness of the question-and-answer process represents the immediateness of the process from "not knowing" to "knowing"; that is, the students finish immediately the state transition from "not knowing" to "knowing." Fourth, sometimes a student doesn't truly understand the essential of Confucius's view when the interpersonal dialogue ends; that is, he doesn't really know. So he has to enter the state of selfknowledge or self-talk. In other words, he has to grasp inward the meaning of Confucius's knowledge perspective.

Socrates's Dialogues presents an opposite view. First, it has two obvious and superficial features: one is that the dialogical process is usually very long. For example, The Republic is a book which records a dialogic process among Socrates and many other persons; the other is that there were usually several people who attended the dialogues. The dialogues of the School of Confucius mostly have one-to-one structures. The men who join one after another of the dialogues in The Republic include Socrates, Cephalus,

\footnotetext{
${ }^{4}$ The Analects is a book written by Confucius's students. It is the classical book of Confucianism which records the words and deeds of Confucius and his students. Socrates's Dialogues was written by his student, Plato.
} 
Thracymuchus, Glaukon, Adeimantos and so on. The dialogue centers on Socrates. The other main dialogist changes frequently.

There are two other, more important features besides the two discussed above: the complexity and open-endedness of dialogue.

The dialogue mechanics of Socrates are very complicated. In the middle there are various exchanges and clashes of opinions. Socrates's Dialogues which exhibits various debate techniques is argumentative. We can fell the logic and wit of Socrates Dialogues because of this argumentative color. Socrates's Dialogues is under the profound influence of the argumentative color in the pedagogical culture of ancient Greece. The sophists, the earliest professional teachers, had developed a kind of dialogic technique which was called sophistry and focused on the rhetorical devices in the dialogical process. The sophists developed rhetoric into an exhibition lore. To a great extent, Socrates rejected the persuasion intent and exhibition character of this kind of rhetoric. But he retained the rhetoric as a kind of means of exploring truth and upgraded it into the state of dialectics. Dialogues shares etymologically a common origin with "dialectics." Socrates's Dialogues reflects the dialectics of Socrates. From this kind of dialogue we can feel the fluidness and contradictoriness of thought. If we regard dialectics as the main character of dialogical teaching, it is doubtful whether the dialogues of the school of Confucius were real dialogues. Overall, the dialogues of the school of Confucius lacked, sadly, argumentative color, power of thought exchange and wit, in comparison with that of the Socratic Dialogues. Perhaps it can be said that Confucius implemented greatly the essence of expository teaching with the form of heuristic teaching.

Socrates' Dialogues also has a distinct feature of open-endedness. This is especially so in the major portion of the early dialogues of Socrates which show an eternal process of argument. To get a common view is almost impossible even though a dialogue has ended. But this creates new questions and suspense for further dialogue. The structures of the dialogic teaching of Confucius usually start from "not knowing" and end with "knowing." The students seem hungry for complete answers and they always could get them from Confucius. Whatever the form of this kind of dialogue is, it centers on the thoughts and opinions of Confucius. Usually Confucius becomes an incarnation of standard knowledge. Sometimes, though, spaces for the students' further thought are left over when the dialogue ends, though usually the thinking of the students ends with a grasping of the meaning of Confucian opinions. That is not true in the Socratic Dialogues, where the dialogues are not for the purpose of supplying or harvesting a fixed answer; on the contrary, Socrates often draws the answers and then questions them or sucks them dry. All in all, in his dialogues, Socrates usually announces "I know nothing" as a start. The process of dialogue is filled with all kinds of challenges and tensions between "not knowing" and "knowing" and at last it ends with "not knowing." No final conclusion is been reached on the subject - there are only deconstructions, but no constructions. Or the only thing that is constructed is that the other dialogists realize with dismay a "not knowing."

\section{The knowledge images of Confucius and Socrates}

In essence, neither Confucius nor Socrates builds a fully equal teacher-student relationship. To some extent, they control the process of dialogue but with basically different ways in which we can discover their different knowledge images.

In general, we can feel that Confucius is a teacher and truth holder who almost knows everything and always undertakes the role of transmitting knowledge and solving doubts. With the opportunity of raising questions (by the students or Confucius), Confucius elaborates his thoughts and evaluates the opinions of the students. Hence, he presents a knowledgeable image of wit. His method and process of teaching are rather simple and forthright. He concentrates on the presentation and 
"insight" of the ideas rather than the dialectics of dialogues. Some ideas would be understand instantly by the students after Confucius's elaborations; however some required them to return to comprehend alone. "Insight" is a kind of important learning method. Once Confucius's ideas and opinions are presented, they seem to be fixed. All that is left is the students' comprehending inside themselves. At this time, the exchanging of thoughts is conducted and completed within the individual. In fact, there is a dialogist in the mind of the students, namely Confucius. Confucius's ideas establish a direction and standard for the insight of the students.

Basically, Confucius is an incarnation of a knowledge standard. Though Confucius was by nature modest and had no intention of seeking the hegemony of knowledge and words, he had a powerful complex of social reform which would drive him into the duty or role of civilizing people with knowledge. This created and presented naturally the profile of Confucius as an incarnation of knowledge and truth. In addition, the emotional power relationship within the School of Confucius boosted and strengthened this kind of profile. Usually the emotion or belief of the students was tightly attached to Confucius. Probably the emotional relationship and dependence prevented them from debating with Confucius. They lacked or reduced greatly the courage and conscious of debating.

Socrates created a unique knowledge image which was different from that of both Confucius and the Sophists. He was much more an explorer than a sophist. The Sophists of ancient Greece were a group of teachers who taught the students knowledge and the shill of debate, and taught them how to win out over the competitors. So they needed to highlight their images as wise and knowledgeable men, for such was a prerequisite for their lives and careers. The sophists were hungry for questions from other people, so they could have a chance to demonstrate and highlight their wit and knowledge. If nobody asked them, some sophists "would be fretful like a cow without being milked in time" (Kierkegaard, 2005, p. 24 ).

The base of Socrates's Dialogues was what he declared: "I know nothing." In his dialogues, Socrates usually tried to be in keeping with this declaration. He seemed to wear a mask behind which he concealed his positions and views. He usually declared modestly that he "knew nothing" and he didn't reveal the mask easily. Through most of his dialogues, we can see that Socrates didn't really appear as a holder of knowledge and truth. Accordingly, he didn't regard himself in the role of solving doubts.

This means that Socrates created a unique figure of a teacher who had a fundamental difference from that of imparting knowledge. In fact, Socrates was a teacher with great wisdom and ability to teach. But his teaching wisdom and ability were embodied in his dialogical ability and technique rather than in the role of imparting knowledge. He had extraordinary listening ability and sensitivity to problems.

The people in the Socrates's Dialogues were not equal. Socrates actually maintained a central position, or Socrates always controlled the trend of dialogue. However, on the side of purpose and as a result of dialogue, Socrates didn't have the color of words in hegemony. The main purpose of Socrates's Dialogues was to help the other dialogists understanding Ego which was the premise of caring Ego. All in all, the purpose of Socrates was to prompt the others to strength their self-consciousness and care for their subjectivity. So Socrates had no intention of controlling the discourse power and subjectivity of others.

Socrates actually controlled the trend of dialogue by dominating the dialogic clues and using dialectics. Perhaps, on the other hand, the most important thing is not who is in the dominating position of a dialogue, but whether the dialogue promotes the awakening of subjectivity. Though Socrates controlled the logical trend of dialogue in form, this kind of control pushed the other dialogists into further thinking. The purpose 
of this kind of dialogue is not to restrain the superiority of the teacher. On the contrary, it can depend on the superiority to promote it more profoundly.

Socrates didn't regard himself as a teacher in the usual sense. It was not his goal to impart knowledge. In other words, Socrates refused the role of teacher according to what Plato said. He regarded himself as a "midwife." Traditionally we define the knowledge relationship between teacher and student as one between "a pail of water" and "a drop of water." This analogy works for Confucius but not for Socrates.

\section{Conclusion}

Confucius and Socrates both declared they did "not know." Their declarations were both true and untrue at the same time. Confucius connected the accumulation of knowledge with learning. In this sense, one person always had a moment of "not knowing." Even sages like Confucius often did not know. But though Confucius declared modestly his "not knowing," he appeared as a knowledge image of truth holder in The Analects of Confucius. The "not knowing" of Socrates meant actually "know nothing" which was related to his preferred orientation of searching for general knowledge. As far as a topic like "justice" is concerned, it is truly hard for us to present a general definition about it. So in this sense the declaration of Socrates is true. But Socrates appeared as a unique torchbearer and prophet when he helped by dialogue the other dialogists to realize their own "knowing nothing."

\section{References}

Dewey, J. (2005). The Quest for certainty (Tongxian Fu, transl.) Shanghai: Shanghai Shiji Publishing Group.

Foucault, M. (2005). The Hermeneutics of the subject (Biping She, transl.) Shanghai: Shanghai People press.

Gross, R. (2005). Socrates's way (Tao Xu and Sifan Li, transl.) Peking: Peking University Press.

Kierkegaard, S. (2005). On irony: With Socrates as the main line (Chenxi Tang, transl.) Peking: China Social Sciences Press.

Lei, Z. (1996). Zhuangzi. Taiyuan: Shanxi Press of Ancient Books. (Original work written about 400 BC )

Liang, Q. (1925/2006). Close Chinese learning for 300 years history. Shanghai: Shanghai Sanlian press.

Qian, M. (1963/2002). New explanation on the analects of Confucius. Peking: Sanlian Press.

Zhang, F. (1995). The Analects. Peking: Peking Yanshan Press.

Zhao, X. (1999). New explanation on the analects of Confucius. Hefei: Anhui University Press.

\section{About the Author}

Zhong Jianwei is Assistant Professor in the College of Teacher Education at Ningbo University. He received his Ph.D. in Curriculum Theory from East China Normal University. His current research interests are in curriculum theory, western philosophy and teacher education. He published his book On the Power of Students (East China Normal University Press) in 2009.

(C) Copyright 2012. The author, Zhong Jianwei, assigns to the University of Alberta and other educational and non-profit institutions a non-exclusive license to use this document for personal use and in courses of instruction provided that the article is used in full and this copyright statement is reproduced. The authors also grant a non-exclusive license to the University of Alberta to publish this document in full on the World Wide Web, and for the document to be published on mirrors on the World Wide Web. Any other usage is prohibited without the express permission of the authors. 